\title{
Dispositivos Móveis, Matemática e Literatura: uma combinação diabólica
}

\author{
Dispositivos Móviles, Matemáticas y Literatura: una combinación diabólica
}

\author{
Mobile Devices, Mathematics and Literature: a diabolic combination
}

\author{
Aline de Lima Brum ${ }^{1}$ \\ Elaine Corrêa Pereira ${ }^{2}$
}

\begin{abstract}
Resumo
O presente artigo tem por objetivo conhecer o potencial pedagógico das tecnologias digitais na produção de histórias matemáticas. Para subsidiar o estudo, apresentamos os três passos para realizar uma investigação matemática, propostos por Ponte, Brocardo e Oliveira (2016), que consistem em: introdução da tarefa, realização da investigação e discussão dos resultados. Na visão desses autores uma investigação não consiste em trabalhar com problemas difíceis, mas com situações que nos interpelam e provocam a busca por respostas. Esse estudo é um recorte de uma pesquisa de mestrado realizada com 24 estudantes do nono ano, do Ensino Fundamental, de uma escola da rede pública, no período de março a dezembro de 2016. As atividades pedagógicas desenvolvidas emergiram da necessidade de reconstruir práticas do cotidiano com os dispositivos móveis, na produção de vídeos, construção de histórias e experimentações com o software GeoGebra. Nessa investigação, de abordagem qualitativa, utilizamos como recurso didático a leitura do livro $\mathrm{O}$ diabo dos números, do escritor alemão Hans Magnus Enzensberger. A metodologia adotada foi a Análise Textual Discursiva, proposta por Moraes e Galiazzi (2011). Os resultados evidenciaram que a inclusão da Literatura como um recurso didático nas aulas de Matemática ampliou as possibilidades de construção do conhecimento e suscitou novos olhares para a diversificação dos espaços de aprendizagem com as tecnologias digitais.
\end{abstract}

Palavras-Chave: Investigação Matemática; Literatura; Matemática; Tecnologias Digitais.

\section{Resumen}

El presente artículo tiene por objetivo conocer el potencial pedagógico de las tecnologías digitales en la producción de historias matemáticas. Para subsidiar el estudio, presentamos los tres pasos para realizar una investigación matemática, propuestos por Ponte, Brocardo y Oliveira (2016), que consisten en: introducción de la tarea, realización de la investigación y discusión de los resultados. En la visión de esos autores una investigación no consiste en trabajar con problemas difíciles, sino con situaciones que nos interpelan y provocan la búsqueda de respuestas. Este estudio es un recorte de una encuesta de maestría realizada con 24 estudiantes del noveno año, de la Enseñanza Fundamental, de una escuela de la red pública, en el período de marzo a diciembre de 2016. Las actividades pedagógicas desarrolladas emergieron de la necesidad de reconstruir prácticas del cotidiano con los dispositivos móviles, en la producción de vídeos, construcción de historias y experimentaciones con el software GeoGebra. En esta investigación, de abordaje cualitativo, utilizamos como recurso didáctico la lectura del libro El diablo de los números, del escritor alemán Hans Magnus Enzensberger. La metodología adoptada fue la Análisis textual Discursiva, propuesta por Moraes y Galiazzi (2011). Los resultados evidenciaron que la inclusión de la Literatura como un recurso didáctico en las clases de Matemáticas amplió las posibilidades de construcción del conocimiento y suscitó nuevas miradas para la diversificación de los espacios de aprendizaje con las tecnologías digitales.

Palabras claves: Investigación Matemática; Literatura; Matemáticas; Tecnologías Digitales.

\footnotetext{
${ }^{1}$ Doutoranda do Programa de Pós-Graduação em Educação em Ciências - FURG; Rio Grande; RS; Brasil; alinebeta@yahoo.com.br

${ }^{2}$ Pós-Doutora pela Universidade Eduardo Mondlane (UEM), Moçambique; elainepereira@prolic.furg.br
} 


\begin{abstract}
The present article aims to know the pedagogical potential of digital technologies in the production of mathematical stories. To support the study, we present the three steps to perform a mathematical investigation, proposed by Ponte, Brocardo and Oliveira (2016), which consist of: introduction of the task, accomplishment of the investigation and discussion of the results. In the view of these authors an investigation does not consist in working with difficult problems, but with situations that challenge us and provoke the search for answers. This study is a cross-section of a master's study carried out with 24 students from the ninth grade of elementary school from a public school in the period from March to December 2016. The pedagogical activities developed emerged from the need to reconstruct everyday practices with mobile devices, in video production, story-telling and experimentation with GeoGebra software. In this qualitative research, we used as a didactic resource the reading of the book The Devil of Numbers, by the German writer Hans Magnus Enzensberger. The methodology adopted was Discursive Textual Analysis, proposed by Moraes and Galiazzi (2011). The results evidenced that the inclusion of Literature as a didactic resource in Mathematics classes expanded the possibilities of knowledge construction and raised new perspectives for the diversification of learning spaces with digital technologies.
\end{abstract}

Keywords: Mathematical Research; Literature; Mathematics; Digital Technologies.

\title{
1. Introdução
}

Cada ser humano tem sua história de vida e nela reflete seus sonhos e as possibilidades de trilhar os caminhos para realizá-los. Somos sujeitos históricos incompletos e, a consciência de tal fato, é que nos leva a educação. Podemos utilizar a visão de Paulo Freire sobre o papel do professor na construção do conhecimento estabelecendo uma relação dialógica com seus educandos no sentido de capacitar os indivíduos a lidar e superar a suas incompletudes. Ou em suas palavras: "Não foi a educação que fez mulheres e homens educáveis, mas a consciência de sua inconclusão é que gerou sua educabilidade" (FREIRE, 1996, p. 64).

As nossas histórias de vida entrelaçam-se com as de outras pessoas por laços de amizade, de amor ou de sangue tecendo uma grande coleção de obras literárias. Provocar o imaginário das crianças e jovens com histórias que permitam expandir as suas concepções sobre determinado assunto, aproximando a vida da escola, é um dos desafios que o educador pode experimentar para transformar a sua sala de aula. De acordo com Moran (2013, p. 34) "aprender hoje é buscar, comparar, pesquisar, produzir, comunicar. Só a aprendizagem viva e motivadora ajuda a progredir. Atualmente, milhões de alunos passam de um ano para o outro sem pesquisar, sem gostar de ler, sem situações significativas vividas”. Segundo este autor é preocupante pensar que os alunos não guardam nada de interessante do que vivenciaram a maior parte do tempo na escola.

Pensando que velhos caminhos nos levam aos mesmos resultados, o paradigma de aprendizagem no qual era priorizada a transmissão, a memorização e a repetição torna-se cada dia mais insuficiente. Nesse sentido, buscamos com o uso do software GeoGebra, dos 
dispositivos móveis, e da Literatura aliada a Matemática criar práticas pedagógicas em sinergia com a geração conectada que chega às escolas e tem o smartphone e a internet como referência para as suas pesquisas e atividades rotineiras. A inclusão da Literatura como recurso didático pedagógico nas aulas de Matemática configura-se, metaforicamente como uma combinação diabólica, por despertar a interconexão das capacidades da língua na construção do conhecimento e do raciocínio lógico matemático.

No contexto do ensino e da aprendizagem, a investigação Matemática é apontada por Ponte, Brocardo e Oliveira (2016) como um poderoso processo de construção do conhecimento. Nessa perspectiva, o nosso objetivo é conhecer o potencial pedagógico das tecnologias digitais na produção de histórias matemáticas, seguindo as estratégias propostas por estes autores para a realização da investigação. As práticas pedagógicas apresentadas neste artigo são um recorte de uma pesquisa de mestrado realizada no período de março a dezembro de 2016, com uma turma de nono ano, do Ensino Fundamental, de uma escola da rede pública, do município de Rio Grande/RS. As atividades desenvolvidas com a turma emergiram da necessidade de reconstruir práticas do cotidiano com os dispositivos móveis, na produção de vídeos e construção de histórias matemáticas, utilizando como recurso didático a leitura do livro O Diabo dos Números, do escritor alemão Hans Magnus Enzensberger.

\section{Perspectiva Teórica}

Moran (2013) afirma que o sucesso pedagógico depende da capacidade do professor de expressar competência intelectual, de mostrar que conhece determinadas áreas do saber, de relacionar os conteúdos com os interesses dos alunos, aproximando a teoria da prática e a vivência da reflexão teórica. Ainda na visão deste autor, as técnicas de comunicação são importantes para o sucesso do professor:

Um professor que se expressa bem, que conta histórias interessantes, que tem feeling para sentir o estado de ânimo da classe, que se adapta às circunstâncias, que sabe jogar com as metáforas, com o humor, que usa as tecnologias adequadamente, sem dúvida consegue bons resultados com os alunos. Os alunos gostam de um professor que os surpreenda, que traga novidades, que varie suas técnicas e seus métodos de organizar o processo de ensino-aprendizagem. (MORAN, 2013, p. 35)

Kenski (2013) infere que a necessidade não é a de usar o meio para fazer o mesmo, é preciso aprender a trabalhar pedagogicamente de forma dinâmica e desafiadora, mudando as práticas e hábitos docentes com o auxílio de softwares, programas especiais e ambientes virtuais. Em princípio, devemos compreender o espaço educativo como o nosso ponto de 
encontro presencial com os alunos, onde vamos conhecer as suas intencionalidades, os seus gostos e aptidões para desenvolver atividades diferenciadas na construção do conhecimento matemático aliado as tecnologias e a literatura.

O ensino de Matemática separado do Português não contribui para a conexão de saberes necessários para se atingir a aprendizagem. Segundo Menezes (2011) as características específicas de cada um dos saberes linguístico e matemático potenciam o outro campo de saber.

A Matemática fornece a língua, e em particular à literatura, estruturação de pensamento, organização lógica e articulação do discurso. Já a língua fornece à Matemática capacidades comunicativas, como a leitura e interpretação de texto (escrito e oral) e também capacidades de expressão (escrita e oral, em particular a discussão). (MENEZES, 2011, p. 69)

A literatura como recurso didático nas aulas de Matemática propicia o desenvolvimento das habilidades dos alunos em interpretar, organizar as ideias, sintetizar os acontecimentos mais importantes do texto e criar novas histórias a partir de uma obra literária. A imaginação e a criatividade ficam por conta dos educandos que ao estarem em contato com as tecnologias digitais são capazes de produzir histórias de forma lúdica e motivadora.

Com a utilização das tecnologias digitais alunos e professores podem diversificar os espaços de aprendizagem disponíveis na sala de aula e nos espaços virtuais. O professor António Nóvoa em uma entrevista afirma que as tecnologias são muito importantes e tem contribuído para mudanças no processo de ensino e de aprendizagem, mas elas sozinhas não alteram o nosso modelo de ensino. Nóvoa insiste na importância das dimensões pessoais no exercício da profissão docente:

Precisamos de professores interessantes e interessados. Precisamos de inspiradores, e não de repetidores. Pessoas que tenham vida, coisas para dizer, exemplos para dar. Educar é contar uma história, e inscrever cada criança, cada jovem, nessa história. É fazer uma viagem pela cultura, pelo conhecimento, pela criação. (NÓVOA, 2010, s.p.)

Borba, Scucuglia e Gadanidis (2015) enfatizam que somos frutos de um momento histórico, que vivemos sempre em conjunto de humanos, que tem as tecnologias historicamente definidas como copartícipes da busca pela educação. É dessa forma que entendemos o processo de educar, que envolve pessoas comprometidas com a vontade de aprender e de ensinar, que buscam além da teoria um motivo para existir e fazer a diferença na vida dos outros. Educar é um processo que exige abandonar a zona de conforto e trilhar a 
zona de risco com a inserção das tecnologias digitais nas aulas de Matemática e a inclusão da literatura como um recurso didático pedagógico.

Precisamos compreender os interesses dos alunos e através do lúdico, da imaginação despertar o gosto pela leitura e pela escrita na construção de histórias matemáticas criando condições para que os alunos interajam e discutam o significado do que leem diversificando os espaços de aprendizagem. Nós, como sujeitos históricos, em constante desenvolvimento, incorporamos as tecnologias ao nosso cotidiano e sem perceber modificamos a nossa história e escrevemos novos roteiros com outras pessoas. Assim, também é na educação, precisamos nos sentir sujeitos da nossa própria história e construir caminhos para desvendar mundos ainda desconhecidos, mas que estão à espera de um toque no smartphone para fazer toda a magia acontecer.

\section{Metodologia}

O presente estudo apresenta um recorte de uma pesquisa de mestrado desenvolvida numa escola da rede pública. Os sujeitos envolvidos são vinte e quatro estudantes do nono ano do ensino fundamental, que tem entre 13 e 17 anos de idade. No período de março a dezembro de 2016 propomos estratégias de inserção das tecnologias digitais nas aulas de Matemática, utilizando smartphones, Facebook, WhatsApp e construção de objetos geométricos com o software de geometria dinâmica GeoGebra.

Os alunos foram incentivados a produzir um vídeo sobre as formas geométricas no seu dia a dia, utilizando os seus smartphones. A proposta da pesquisadora consistiu na exploração de ambientes ou locais que fizessem parte da vivência dos alunos, ou seja, o trajeto percorrido da casa até a escola, o quarto deles ou algum lugar predeterminado pelo grupo. As produções dos vídeos sobre o tema "Pesquisando as formas geométricas no meu dia a dia" envolveu a criatividade dos alunos, um trabalho em grupo com diversão, música, dança e entrevistas na rua. Cada grupo se destacou pela sua originalidade e espírito de equipe, explorando alguns pontos turísticos da nossa cidade e reconhecendo as formas geométricas no seu cotidiano.

Aliado a elaboração do vídeo utilizamos como recurso didático pedagógico a leitura do livro O Diabo dos Números. Este livro conta a história de um menino de onze anos, que usa um pijama azul e tem pesadelos a noite. O menino atende pelo nome de Robert e vive fascinantes aventuras em seus sonhos mirabolantes. Certo dia, Robert andava intrigado com esses pesadelos e apareceu no seu sonho o Teplotaxl, também conhecido como o diabo dos números. Em uma sequência de doze sonhos, Robert e Teplotaxl encontram-se em diferentes 
lugares e vivenciam as mais belas aventuras envolvendo os números, a geometria, a calculadora, etc. O menino do pijama azul começa a dormir mais cedo, na expectativa de sonhar com o diabo dos números. E esse diabo, que no início, parecia descontrolado e sem paciência vai se tornar um grande amigo de Robert, demonstrando seu lado divertido e amoroso.

Essas histórias vividas por Robert e Teplotaxl inspiraram atividades sobre o medo que sentimos da Matemática quando estamos na escola e apresentamos dificuldades em relação a algum conteúdo. A turma foi dividida em duplas e cada uma ficou responsável pela leitura de um capítulo do livro, ou seja, cada dupla explorou as aventuras dos sonhos de Robert com o diabo dos números e em grupos criaram a sua própria história. A prática pedagógica desenvolvida consistiu na produção de um vídeo, intitulado: "Brincando com o Diabo dos Números", no qual os estudantes poderiam reproduzir cenas do livro adaptadas a sua realidade e aos seus medos de aprender Matemática na escola. Para tanto, essas histórias produzidas em vídeo, subsidiaram outras estratégias de investigação Matemática utilizando o software de geometria dinâmica GeoGebra na visualização e construção de conjecturas.

Para a produção dos dados foram utilizados como instrumentos o Diário da Pesquisadora, um Portfólio Virtual construído com os alunos no Facebook e um grupo no WhatsApp. A cada prática pedagógica desenvolvida, os alunos eram incentivados a digitar no Portfólio Virtual suas reflexões sobre as aprendizagens, as dificuldades, os anseios e as descobertas ao utilizar as tecnologias digitais nas aulas de Matemática.

As percepções da pesquisadora sobre as construções de conceitos matemáticos, a motivação da turma no desempenho e na elaboração da ação educativa foram registradas no Diário da Pesquisadora. Outra estratégia utilizada para interagir com os alunos foi a criação de um grupo no WhatsApp, com a intenção de promover a interação e a comunicação mais rápida. Nesse espaço, a pesquisadora orientou os alunos e disponibilizou materiais para as próximas atividades a serem desenvolvidas, propiciando a comunicação entre os sujeitos da pesquisa em um ambiente que favoreceu a aprendizagem colaborativa.

$\mathrm{Na}$ análise dos dados produzidos adotamos o método da Análise Textual Discursiva (ATD) proposta por Moraes e Galiazzi (2011). Essa metodologia foi escolhida por ser de abordagem qualitativa e permitir a compreensão do fenômeno investigado no ambiente educativo. O ciclo de análise é composto por três momentos auto-organizados: desmontagem dos textos, estabelecimento de relações e captando o novo emergente.

Assim, partindo do pressuposto que a ATD opera com significados construídos a partir de um conjunto de textos que possibilitam múltiplas interpretações, tomamos como corpus da 
análise as produções textuais dos alunos registradas no Portfólio Virtual. Dentro dessa perspectiva, observamos que o objetivo da ATD é a construção de metatextos que explicitam algo importante que o pesquisador tem a dizer sobre o fenômeno que investigou.

\section{Resultados}

Apresentamos um recorte da análise das compreensões emergentes sobre o fenômeno investigado, no metatexto intitulado "Tecnologia e Matemática: um novo olhar para a Matemática que transcende os muros da escola”. O matemático George Pólya revela-nos as duas faces da Matemática: "é a ciência rigorosa de Euclides, mas é também algo mais... A Matemática em construção aparece como uma ciência experimental, indutiva" (PÓLYA, 1995, p.VI). Para compreender a verdadeira natureza da Matemática, precisamos abandonar velhas convicções de que essa ciência está pronta e ampliar nosso entendimento, em uma perspectiva dinâmica que possibilita a investigação e a construção de conceitos matemáticos.

Ponte, Brocardo e Oliveira (2016, p. 13) afirmam que investigar para os matemáticos “é descobrir relações entre objetos matemáticos conhecidos ou desconhecidos, procurando identificar as respectivas propriedades". Outro ponto importante destacado pelos autores é que uma investigação matemática não precisa abordar problemas difíceis, mas trabalhar com questões que nos interpelam e provocam a busca por respostas que não estão prontas. Para entender como podemos realizar uma investigação matemática na sala de aula, precisamos desenvolver três fases (em uma aula ou conjunto de aulas), que consistem em:

(i) introdução da tarefa, em que o professor faz a proposta a turma, oralmente ou por escrito, (ii) realização da investigação, individualmente, aos pares, em pequenos grupos ou com toda turma, e (iii) discussão dos resultados, em que os alunos relatam aos colegas o trabalho realizado. (PONTE; BROCARDO; OLIVEIRA, 2016, p. 23)

Essas fases podem ser realizadas de diferentes maneiras, de acordo com a intencionalidade do professor, tendo sempre em vista que podemos planejar o modo de começar uma investigação, mas poderemos nos surpreender com os resultados. No início, a primeira etapa, o professor conversa com a turma e expõe a proposta de trabalho, conscientizando os participantes da colaboração de cada um na realização da investigação. $\mathrm{Na}$ segunda etapa, os alunos se dividem em grupos, de preferência por afinidades, para que o trabalho desenvolvido represente a personalidade de cada integrante, facilitando a organização e divisão das tarefas. Por fim, a terceira etapa, representa a divulgação dos resultados dos 
grupos para a turma, que pode ser feito de modo presencial, na sala de aula, ou utilizando um ambiente virtual de aprendizagem.

Alguns aspectos que merecem a nossa atenção quando desafiamos os estudantes a desenvolver uma investigação são considerar as suas múltiplas ideias, orientar as divergências entre eles, acompanhar seus progressos, esclarecer eventuais dúvidas e organizar o período de entrega dos resultados. Percebemos nesse último aspecto, que diferente das aulas tradicionais, da cobrança de datas para entrega dos trabalhos; em uma atividade de investigação a flexibilidade deve ser uma característica do professor, entendendo que o prazo pode ser ampliado conforme a necessidade ou imprevisibilidade de cada grupo. $\mathrm{O}$ aluno precisa se sentir motivado para discutir suas ideias com o professor e com os colegas, estabelecendo uma parceria no ambiente de aprendizagem e, consequentemente, a valorização do seu trabalho.

Tomemos como exemplo as falas dos estudantes ${ }^{3}$ sobre a investigação realizada: "Eu achei uma experiência muito legal e diferente, mesmo já conhecendo as formas geométricas, tive um outro olhar para as coisas na rua e foi um jeito de aprender mais" (TASHA, 2016). O aluno Hulk afirma que: "a principal aprendizagem foi que a matemática não está só dentro da sala de aula, nós convivemos com a matemática e não percebemos" (HULK, 2016). Nesse sentido, a aluna Açúria contribui: "Elaborar um vídeo para o trabalho de matemática foi muito legal, pude aprender mais sobre geometria, além de perceber o quanto a matemática está presente no nosso dia-a-dia" (AÇÚRIA, 2016).

Esta percepção de que a Matemática está presente em todos os segmentos de nossas vidas é expressa pela maioria dos alunos na fase inicial da investigação, a qual se destaca como decisiva na elaboração e construção de conjecturas. É nessa fase que os alunos vão se familiarizando com o ambiente que os cercam e fazendo relações do que se aprende dentro e fora da sala de aula. Nessa perspectiva Moran (2013) enfatiza que:

É importante conectar sempre o ensino com a vida do aluno. Chegar ao aluno por todos os caminhos possíveis: pela experiência, pela imagem, pelo som, pela representação (dramatizações, simulações), pela multimídia, pela interação on-line e off-line. (MORAN, 2013, p. 69)

\footnotetext{
${ }^{3}$ Os nomes dos estudantes são fictícios para preservar as suas identidades. A proposta era escolher um nome que representasse a sua interação no meio digital, poderia ser um login utilizado em aplicativos ou uma palavra referente ao ensino de Matemática.
} 
Moran alerta que viveremos novos tempos de aprendizagem em sala de aula, priorizando a pesquisa em tempo real, atividades individuais e grupais on-line, transformando o ambiente escolar em espaços de aprendizagem colaborativa e personalizada. Ponte, Brocardo e Oliveira (2016, p. 26) afirmam que o trabalho em grupo "potencia o surgimento de várias alternativas para a exploração da tarefa”. No entanto, se os alunos não estão acostumados a trabalhar em grupo e realizar investigações, a inserção desses dois elementos novos pode gerar alguns conflitos que necessitam da intervenção docente. Sobre a dinâmica do trabalho em grupo, destacamos dois trechos contrastantes nas falas dos alunos:

\begin{abstract}
No início parecia que ia dar tudo certo, nos reunimos pra montar o roteiro e fluiu algumas ideias, mas no fim não usamos nenhuma delas, o engajamento de quase todos foi legal na expectativa de montar o vídeo aí foi caindo, e de repente estávamos no regatas gravando, sem roteiro e tbm sem saber o que estávamos fazendo ali, eu tive a ideia de escrever as equações no papel manchado com sangue e essa seria apenas a primeira aparição do diabo dos números ensinando ele a resolver, eram pra ter mais cenas depois daquilo envolvendo mais partes da história do livro, como no meu capítulo, ele poderia ter ficado doente e aí falar também dos números primos, envolver mais a história, porém queríamos fazer algo bem original, mas não deu muito certo, eu esperava mais do trabalho, do grupo inteiro. (MONSTRO, 2016)
\end{abstract}

O aluno Monstro relata a prática pedagógica proposta à turma sobre o vídeo, a partir da leitura dos capítulos do livro O Diabo dos Números. O grupo no início da elaboração do roteiro se mostrou empolgado tentando envolver o capítulo do livro com uma cena de terror e de medo da Matemática. Com o passar do tempo e na concretização do trabalho, as ideias elaboradas não surtiram o efeito esperado, os horários dos alunos não coincidiram para a produção do vídeo e alguns alunos não participaram das cenas. A produção final envolveu três alunos que tomaram a liderança da criação da história e concluíram a dramatização. A situação explicitada sobre o trabalho em grupo revela a dificuldade de organização das ideias e estruturação das cenas. Já a estudante Delta expressa outra visão sobre a prática desenvolvida:

Tivemos uma certa dificuldade em questão do roteiro, não fazíamos ideia do que fazer. Outro problema que tivemos foi pra começarmos a gravar, as ideias foram surgindo bem no final do tempo dado pela professora, então a correria de gravar foi um pouco tensa. Gravamos em 2 dias seguidos, sexta e sábado, a tarde inteira. Aconteceram alguns desencontros e indisponibilidades de horários na sexta-feira, mas no sábado conseguimos gravar tudo sem nenhum problema. (DELTA, 2016)

Nesse grupo, a aluna destaca a dificuldade de elaborar um roteiro para a gravação do vídeo, mesmo tendo os capítulos do livro, não conseguiam organizar as ideias mais importantes. Com o prazo de entrega se aproximando, os alunos organizaram-se em dois dias 
e concluíram o vídeo. Outro ponto evidenciado pela aluna diz respeito à motivação e à participação de todos na realização da atividade: "Gravar foi um pouco difícil porque ficávamos rindo o tempo inteiro, algumas cenas (principalmente a do diabo) foram muito engraçadas. Todos colaboraram, participaram e ajudaram em cada parte da gravação" (DELTA, 2016). Delta relata ainda: "Sinceramente, me surpreendi muito com o resultado do vídeo e com a participação e colaboração de todos para o mesmo" (DELTA, 2016).

Como podemos observar, com base nos relatos apresentados, o papel do professor como orientador nesse processo é fundamental, estimulando a colaboração e ajuda mútua, fazendo os alunos refletirem sobre a investigação, registrando suas dificuldades, descobertas e novas aprendizagens. Esse processo de reflexão ajuda a compreender as estratégias utilizadas na construção de conjecturas. Contudo, a interação entre professores e alunos se diferencia das aulas tradicionais, revelando uma nova prática pedagógica mais dialógica, de modo que o aluno pode despertar aspectos desconhecidos pelo professor. Para tanto, precisamos estabelecer uma relação de confiança com nossos estudantes, propiciando ambientes de aprendizagem mais flexíveis que transcendam os muros da escola.

De acordo com Moran (2013), com o tempo fará sentido repensar os horários, os espaços e as formas de organizar os processos de ensino e aprendizagem:

É uma questão de amadurecimento e de profundo intercâmbio de experiências para construir propostas mais arrojadas, testadas e aceitas. Demorará mais do que gostaríamos, mas a chegada das tecnologias móveis às salas de aula é como um cavalo de Troia. Em curto prazo, parece que não haverá muitas mudanças; mas, em médio prazo, ela nos obrigará a reorganizar o tempo, o espaço e a forma de ensinar e aprender. (MORAN, 2013, p. 68)

Nesse novo contexto, em que buscamos reorganizar a prática pedagógica com a inserção dos dispositivos móveis na construção de conceitos matemáticos, observamos nas falas dos alunos a percepção de que a Matemática não se reduz aos cálculos:

\footnotetext{
Quando falam matemática eu só imagino contas e se falar em formas geométricas eu vou pensar em contas também, mas que envolvem formas, tipo o perímetro. Mas depois desse trabalho, eu vejo que as formas geométricas estão em todo lugar, fiquei muito impressionada com esse trabalho, pois achei que seria difícil achar formas geométricas, mas não, foi o oposto, pois assim que saímos para fazer o trabalho percebemos que praticamente tudo tinha uma forma geométrica. Foi o melhor trabalho que já fiz. (CARIOQUINHA, 2016)
}

Assim como a estudante Carioquinha, a aluna Jurema também percebeu na realização do trabalho envolvendo as tecnologias digitais que: "Esse trabalho contribuiu sim na nossa 
aprendizagem, matemática não envolve só números, envolve tudo, até formas geométricas" (JUREMA, 2016). O aluno Betão Mutante complementa: “A experiência de fazer um vídeo em matemática foi muito legal, pois nunca imaginei isso nessa matéria" (BETÃO MUTANTE, 2016). A motivação dos estudantes ao desenvolverem essas atividades suscita a busca de novas metodologias que atendam às exigências da sociedade informatizada. De acordo com Behrens (2013):

Em face da nova realidade, o professor deverá ultrapassar seu papel autoritário, de dono da verdade, para se tornar um investigador, um pesquisador do conhecimento crítico e reflexivo. O docente inovador precisa ser criativo, articulador e, principalmente, parceiro de seus alunos no processo de aprendizagem. Nessa nova visão, o professor deve mudar o foco do ensinar para reproduzir conhecimento e passar a preocupar-se com o aprender e, em especial, o "aprender a aprender", abrindo caminhos coletivos de busca e investigação para a produção do seu conhecimento e do seu aluno. (BEHRENS, 2013, p. 77)

$\mathrm{Na}$ visão dessa autora, os professores e alunos deveriam estar em um processo permanente de aprender a aprender, mudando o foco do ensinar para os caminhos que levem ao aprender. O professor que ainda acredita que o ensino para se concretizar necessita de uma quantidade substancial de informações com listas de exercícios repetidos recebe como retorno dos alunos o desinteresse nas aulas e, na maioria das vezes, eles nem se lembram do que estudaram na aula anterior. Essa realidade é identificada nas falas dos estudantes que valorizam o uso da tecnologia nas aulas de Matemática: "Para mim esse trabalho chegou para quebrar a rotina e sair do padrão de sala de aula, a proposta era fazer algo diferente de só copiar e fazer, e deu certo" (AO QUADRADO, 2016).

Nessa perspectiva, o aluno Bin Laden relata: "Curti bastante a aula com o geogebra, porque é um jeito diferente de aprender a matemática saindo dos exercícios no caderno que fica muitas vezes enjoativo (nada contra), enfim, foi bem show... tomara que tenha mais vezes" (BIN LADEN, 2016). Ao trabalhar com o software de geometria dinâmica GeoGebra, os alunos constroem objetos geométricos, experimentam e visualizam a Matemática em movimento, o que torna a aula mais interessante do que apenas fazer exercícios no caderno. A aluna Aqualien também gostou da aula com o GeoGebra: "Eu aprendi de uma maneira fácil, rápida e eficiente como utilizar as formas através do geogebra. Eu explorei bastante o aplicativo e achei bastante informações e outras formas geométricas, eu acho que deveríamos ter mais aulas como esta!" (AQUALIEN, 2016). 
Além de considerar a aula diferente com a utilização do software e dos dispositivos móveis, os alunos valorizaram a investigação e as descobertas de novas ferramentas. Esses aspectos do processo investigativo podem ser observados na fala do aluno Mitchell:

\begin{abstract}
Passamos uma aula legal entre turma, onde aos poucos os risos e os aprendizados foram se misturando... Uma aula onde a força de vontade, a matemática e a diversão andaram de mãos dadas! Nos permitiu enxergar o quanto a tecnologia pode ajudar a entender melhor toda a parte da geometria! Eu amei fazer esse trabalho, pois vai muito além de apenas uma aula comum (em todos os sentidos) vou guardar tudo que estou aprendendo e todos esses momentos comigo... quando é a próxima? (MITCHELL, 2016)
\end{abstract}

Talvez esse seja o maior desafio do educador: perceber a matemática por meio dos olhos dos seus alunos, criando condições para que em parceria, professores e alunos transformem a sala de aula em um ambiente prazeroso de construção de conhecimentos, em uma interação inundada de afetividade. Mais uma vez, verificamos o quanto os alunos buscam integrar aos seus conhecimentos matemáticos a investigação e que o professor precisa estimular esse registro. De acordo com Ponte, Brocardo e Oliveira (2016, p. 30), "O professor precisa estar atento a todo esse processo de formulação e teste de conjecturas, para garantir que os alunos vão evoluindo na realização de investigações". Desse modo, precisamos explorar diferentes assuntos possibilitando um novo olhar do aluno que o ajude a refletir sobre o que está fazendo, como exemplifica a aluna Tasha na construção do fractal utilizando o software GeoGebra:

Fractal é uma figura que pode ser quebrada em pequenos pedaços e pode se transformar em várias formas e fazer um desenho. Existe fractal na natureza, fractal abstrato, entre outros. Tentamos fazer um floco de neve usando geometria fractal e mesmo não conseguindo fazer, pois travou o GeoGebra, achei muito legal. (TASHA, 2016)

Ponte, Brocardo e Oliveira (2016) reforçam o papel fundamental que o registro escrito desempenha quando realizamos uma investigação matemática, permitindo-nos acompanhar os avanços dos estudantes, a explicitação de suas ideias, a construção de conjecturas e a capacidade de se comunicarem matematicamente. Nesse caso, a aluna expressa o que observou na construção do floco de neve, registra o seu entendimento sobre a geometria fractal, a percepção desses elementos na natureza e ressalta a imprevisibilidade de se trabalhar com a tecnologia. O professor deve estar preparado para trabalhar com as tecnologias digitais consciente de que imprevistos acontecem, mas que podem ser superados a medida que o 
trabalho vai se desenvolvendo e consegue enxergar nos alunos o interesse e a motivação que há muito tempo se extinguiu.

Nesse contexto, Imbernón (2011) afirma que a aquisição de conhecimentos por parte do professor é um processo amplo e não linear:

\begin{abstract}
A mudança nas pessoas, assim como na educação, é muito lenta e nunca linear. Ninguém muda de um dia para o outro. A pessoa precisa interiorizar, adaptar e experimentar os aspectos novos que viveu em sua formação. A aquisição de conhecimentos deve ocorrer da forma mais interativa possível, refletindo sobre situações práticas reais. (IMBERNÓN, 2011, p. 16-17)
\end{abstract}

No decorrer de uma investigação, tanto aluno quanto professor aprende que cada pessoa tem o seu ritmo de aprendizagem e que "aprender para pôr em prática uma inovação supõe um processo complexo" (IMBERNÓN, 2011, p.17). Para superar essa complexidade, o professor deve buscar estratégias de ensino e aprendizagem que aproximem a vida da escola, interagindo com seus alunos, descobrindo seus interesses e dando-lhes autonomia para que consigam pensar matematicamente. Nesse processo de pôr em prática a inserção das tecnologias digitais móveis na sala de aula, descobrimos um universo de possibilidades de transformar o ambiente educativo em "um conjunto de espaços ricos de aprendizagens significativas, presenciais e digitais, que motivem os alunos a aprender ativamente, a pesquisar o tempo todo, a serem proativos, a saber tomar iniciativas e interagir" (MORAN, 2013, p. 31).

Ao desenvolver um trabalho de pesquisa e investigação com os alunos, enfrentamos a superação de nossos próprios medos e limitações. Nós sabemos que mudar é um processo lento que gera conflitos internos entre o que aprendemos, ensinamos e a educação que desejamos, mas possibilita a experimentação de práticas pedagógicas reais, que tão logo recebemos os frutos, como podemos nos emocionar nas palavras desse aluno:

Eu gostei muito de fazer esse trabalho, pois nos permitiu enxergar a matemática de uma forma diferente, e nos permitiu ver que algumas pessoas realmente têm medo de contas, e às vezes nem sabem que algumas são super fáceis, basta paciência e boa vontade para resolver. Acho que todos os profs deveriam seguir o exemplo da minha sora de matemática doidinha, que sempre propõe os melhores trabalhos e sempre tenta incentivar e cativar cada um de nós a ser melhor a cada dia. Para ensinar matemática tem que gostar, tem que pensar em ideias e formas de deixar tudo menos maçante. Gostei muito da oportunidade de gravar esse vídeo, me permitiu enxergar a matemática com outros olhos! (MITCHELL, 2016)

As respostas recebidas dos alunos foram extraordinárias, a motivação ao realizar as atividades e a divulgação dos resultados para a turma, utilizando o ambiente virtual de 
aprendizagem possibilitou um novo olhar para a Matemática com a inserção das tecnologias, que transcendeu os muros da escola e até a nossa própria imaginação. A seguir, apresentaremos algumas considerações.

\section{Considerações}

Desenvolver um trabalho de investigação matemática, em uma escola pública, com a inserção dos dispositivos móveis é um grande desafio para o educador que traz na sua trajetória de vida a concepção de um ensino pautado em conteúdos e avaliações tradicionais. Faz parte de um rasgar-se e remendar-se, de acreditar que essa geração conectada que chega às escolas tem sede de conhecimento e tem o mundo na palma da mão, a um toque na tela do seu smartphone. Negar a existência e potencialidade das tecnologias nas nossas vidas é negar o momento histórico em que vivemos.

Ao propor práticas pedagógicas de produção de vídeos, construção de histórias matemáticas a partir da leitura do livro $\mathrm{O}$ diabo dos números, experimentação da geometria fractal com o software GeoGebra, a nossa sala de aula se expandiu e mostrou o quanto a interação entre professor e alunos se diferencia, revelando uma nova prática pedagógica mais dialógica. Percebemos nas falas dos estudantes o quanto a inserção das tecnologias ajudou a entender melhor a geometria e enxergar que a Matemática está presente em todos os lugares.

O papel do professor como orientador é fundamental em uma investigação matemática, estimulando a colaboração e ajuda mútua, fazendo os alunos refletirem e registrarem suas dificuldades, descobertas e novas aprendizagens. A inclusão da literatura como um recurso didático pedagógico nas aulas de Matemática ampliou as possibilidades de construção do conhecimento e suscitou novos olhares para a diversificação dos espaços de aprendizagem com as tecnologias digitais.

\section{Referências}

BEHRENS, M. A. Projetos de aprendizagem colaborativa num paradigma emergente. In: MORAN, J. M.; MASETTO, M. T.; BEHRENS, M. A. Novas tecnologias e mediação pedagógica. 21.ed. rev. e atual. Campinas, SP: Papirus, 2013, p. 73-140.

BORBA, M. C.; SCUCUGLIA, R. R. S.; GADANIDIS, G. Fases das tecnologias digitais em Educação Matemática: sala de aula e internet em movimento. 1.ed.; 1. reimp. Belo Horizonte: Autêntica Editora, 2015. 
ENZENSBERGER, H. M. O Diabo dos Números. 1.ed. São Paulo: Companhia das Letras, 2009.

IMBERNÓN, F. Formação docente e profissional: formar-se para a mudança e a incerteza. 9.ed. São Paulo: Cortez, 2011.

KENSKI, V. M. Tecnologias e tempo docente. Campinas: Papirus, 2013.

MENEZES, L. Matemática, Literatura e Aulas (2011). Disponível em: http://www.esev.ipv.pt/mat1ciclo/Nova\%20pasta/_EM115_pp67-71_4f1d94c118b47_H.pdf. Acesso em: 22 nov. 2018.

MORAES, R.; GALIAZZI, M. C. Análise Textual Discursiva. 2.ed. rev. Ijuí: Editora Unijuí, 2011.

MORAN, J. M. Ensino e aprendizagem inovadores com apoio de tecnologias. In: MORAN, J. M.; MASETTO, M. T.; BEHRENS, M. A. Novas tecnologias e mediação pedagógica. 21.ed. rev. e atual. Campinas, SP: Papirus, 2013, p. 11-72.

NÓVOA, A. (2010). "Profissão: Docente". Entrevista concedida via e-mail ao repórter Paulo de Camargo. Revista Educação, n. 154, nov. Disponível em:

http://revistaeducacao.uol.com.br/formacao-docente/154/artigo234711-1.asp . Acesso em: 28 dez. 2018.

PÓLYA, G. A Arte de Resolver Problemas. Rio de Janeiro: Interciência, 1995.

PONTE, J. P.; BROCARDO, J.; OLIVEIRA, H. Investigações Matemáticas na Sala de Aula. 3.ed. rev. ampl.; 2. reimp. Belo Horizonte: Autêntica Editora, 2016. 